\title{
Preliminary Studies on Unusual Magnetic Diurnal Variation on Hengchun Peninsula
}

\author{
Chun-Rong Chen ${ }^{1}$, Horng-Yuan Yen ${ }^{1, *}$, Chieh-Hung Chen ${ }^{2}$, Ying-Yuan Lee ${ }^{1}$, Yu-Tsung Lo ${ }^{1}$, and \\ Tzay-Chyn Shin ${ }^{3}$ \\ ${ }^{1}$ Department of Earth Sciences, National Central University, Taoyuan, Taiwan, R.O.C. \\ ${ }^{2}$ Department of Earth and Environmental Sciences, National Chung Cheng University, Chiayi, Taiwan, R.O.C. \\ ${ }^{3}$ Central Weather Bureau, Taipei, Taiwan, R.O.C.
}

Received 10 June 2014, revised 17 April 2015, accepted 4 June 2015

\begin{abstract}
The geomagnetic total intensity data recorded by a geomagnetic network in Taiwan comprised of 11 permanent proton magnetometers was used to compute diurnal variation ranges to examine if any discrepancies were present. Diurnal variations with similar ranges were obtained from all stations except for the $\mathrm{HC}$ station. The ranges at the HC station are often two times greater than those recorded at the other stations. This is an interesting phenomenon that requires considerable attention. Eight temporary stations were set up between the Taitung (TT) and Hengchun (HC) stations, distributed evenly over the Hengchum peninsula during 13 September 2012 to 25 January 2013 to clarify the phenomenon. The local stations in Taiwan are compared with 2 international stations to explain the diurnal ranges resulting from the interaction between solar activities and the Earth's main geomagnetic field and/or local effects. Analytical results show that the unusually large diurnal ranges were observed mainly on the Hengchun peninsula. The surrounding the sea water produces the magnetic coast effect.
\end{abstract}

Key words: Geomagnetic, Diurnal variation, Coast effect

Citation: Chen, C. R., H. Y. Yen, C. H. Chen, Y. Y. Lee, Y. T. Lo, and T. C. Shin, 2016: Preliminary studies on unusual magnetic diurnal variation on Hengchun peninsula. Terr. Atmos. Ocean. Sci., 27, 21-28, doi: 10.3319/TAO.2015.06.04.01(T)

\section{INTRODUCTION}

A network of 8 ground-based geomagnetic stations, distributed evenly around Taiwan Island was established in 1988 (Yen et al. 2004). Proton magnetometers with a resolution of $0.1 \mathrm{nT}$ routinely observed changes in the geomagnetic total intensity field with a sampling interval of $10 \mathrm{~min}$ utes at the Liyutan (LY), Tsengwen (TW), Hengchun (HC), Taitung (TT), Yuli (YL), Hualien (HL), and Neicheng (NC) stations. In contrast, the Lunping (LP) station with a long sampling interval of 5 minutes is considered the reference station because it is located in an aseismic area in northwestern Taiwan. In 2002 new proton magnetometers replaced the original ones and the sampling interval was decreased to 1 minute. The Yeheng (YH), Shuanlung (SL), and Pingtung (PT) stations, set up in the Central Mountain Range from northern to southern Taiwan, were added to the network to provide good coverage in the mountain ranges. Note that the

\footnotetext{
* Corresponding author

E-mail:yenhy@earth.ncu.edu.tw
}

geomagnetic field nearby the LP station has been intensely affected by artificial noise since 2002. The Kinmen (KM) station, located on the southeastern margin of the Eurasia plate and located in another aseismic area, replaced the LP station as the reference station. The network is comprised of 11 stations (Table 1) and has been in operation by the Central Weather Bureau, Taiwan since 2007. The station sampling interval was modified to $1 \mathrm{sec}$ in 2007.

The geomagnetic stations in Taiwan were set up far away from visible iron, power lines and artificial buildings to yield quality data free from artificial noise. Chen et al. (2009) examined the geomagnetic data in different observation periods using the Chapman-Miller method (Chapman and Miller 1940). Analytical results show that a tiny lunar component (Chapman and Bartels 1940), which is often hidden behind obvious diurnal variations, can be clearly retrieved from the recorded data. This suggests that the Taiwan recorded geomagnetic data is recorded in high-quality. These valuable data have been utilized to correct the solar 
effects when the geomagnetic survey was processed in the Taiwan area (Yen et al. 2009; Chen et al. 2014; Hsieh et al. 2014) and to study interesting phenomena associated particularly with seismo-magneitc anomalies (Chen et al. 2006, 2011, 2012, 2013; Wen et al. 2012). Chen et al. (2004) found that changes in the annual geomagnetic field values in Taiwan approached $0 \mathrm{nT}$ about 2 years before the Chi-Chi earthquakes (on 20 September 1999; UTC). Two months prior to the Chi-Chi earthquake, Yen et al. (2004) observed intense fluctuations in magnetic anomalies with amplitudes of about 200 (150) nT at the northern (southern) end of the Chelungpu fault at the LY (TW) station. Liu et al. (2006) found that the ratios of diurnal variation ranges computed between the reference and a monitoring station would depart the median for these ratios (for stations with similar geomagnetic latitudes) a few days prior to earthquakes. Chen et al. (2010) reported that magnetic fields with changes in the ratios prior to earthquakes were often observed at nearby fault planes and/ or an anomalous belt derived from the focal mechanism parameters. However, the geomagnetic data recorded at the $\mathrm{HC}$ station has often been ignored from these aforementioned studies due to the unusual range of diurnal variations.

Geomagnetic total intensity data recorded at the 18 local stations [10 permanent stations (HC, HL, KM, LY, NC,
SL, TT, TW, YH, and YL) from the Central Weather Bureau, Taiwan and 8 temporary stations (CP, ELB, MS, SG, $\mathrm{SH}, \mathrm{SM}, \mathrm{SX}$, and TH) set between TT and HC on 13 September 2012 to 25 January 2013; also see Fig. 1 and Table 1] in Taiwan is utilized in this study to expose the possible factors for the unusually large ranges in diurnal variations at the $\mathrm{HC}$ station. Geomagnetic data recorded at 2 international stations [the Zhaoqing (GZH) and Phuthuy (PHU) stations], were retrieved from the World Data Center (http:// wdc.kugi.kyoto-u.ac.jp) and located at similar geomagnetic latitudes with the $\mathrm{HC}$ station, are also integrated together for examination. Theses geomagnetic data were compared with modeled values from IGRF (International Geomagnetic Reference Field) to examine the unusually large diurnal ranges resulting from either the interaction between solar activities and the Earth's main geomagnetic field or local effects. The geomagnetic latitude effects on diurnal ranges were eliminated using a linear relationship to determine the areas with unusually large diurnal ranges.

\section{DATA ANALYSIS AND ANALYTICAL RESULTS}

Figure 2 shows the changes in the geomagnetic total intensity field at the 10 permanent stations in Taiwan during

Table 1 . The basic information, ratio and ratio difference at used stations in this study.

\begin{tabular}{|c|c|c|c|c|c|c|}
\hline Station & Country & Longitude $\left(^{\circ}\right)$ & Latitude $\left(^{\circ}\right)$ & Geomagnetic Latitude $\left(^{\circ}\right)$ & Ratio & Ratio Difference \\
\hline LP & Lunping & 121.17 & 25.00 & 15.30 & $\mathrm{X}$ & $\mathrm{X}$ \\
\hline $\mathrm{NC}$ & Taiwan & 121.67 & 24.71 & 15.02 & 1 & -0.0324 \\
\hline $\mathrm{YH}$ & Taiwan & 121.37 & 24.66 & 14.98 & 1.0729 & 0.0404 \\
\hline KM & Taiwan & 118.41 & 24.45 & 14.71 & 1.0984 & 0.0649 \\
\hline $\mathrm{HL}$ & Taiwan & 121.60 & 24.07 & 14.64 & 1.0143 & -0.0810 \\
\hline LY & Taiwan & 120.77 & 24.35 & 14.39 & 0.9536 & -0.0195 \\
\hline SL & Taiwan & 120.90 & 23.79 & 14.08 & 1.0155 & -0.0202 \\
\hline YL & Taiwan & 121.29 & 23.34 & 13.65 & 1.1350 & 0.0977 \\
\hline TW & Taiwan & 120.52 & 23.25 & 13.53 & 1.0748 & 0.0370 \\
\hline $\mathrm{GZH}$ & China & 112.40 & 23.00 & 13.27 & 1.0522 & 0.0135 \\
\hline TT & Taiwan & 121.06 & 22.79 & 13.09 & 1.2820 & 0.2427 \\
\hline PT & Taiwan & 120.65 & 22.70 & 12.99 & $\mathrm{X}$ & X \\
\hline MS & Taiwan & 120.64 & 22.62 & 12.92 & 1.3579 & 0.3180 \\
\hline $\mathrm{TH}$ & Taiwan & 120.72 & 22.41 & 12.70 & 1.4449 & 0.4041 \\
\hline $\mathrm{CP}$ & Taiwan & 120.80 & 22.23 & 12.53 & 1.2162 & 0.1748 \\
\hline $\mathrm{SM}$ & Taiwan & 120.77 & 22.12 & 12.42 & 1.7312 & 0.6894 \\
\hline SG & Taiwan & 120.81 & 22.07 & 12.37 & 1.4120 & 0.3701 \\
\hline SX & Taiwan & 120.84 & 21.99 & 12.29 & 2.7646 & 1.7223 \\
\hline $\mathrm{SH}$ & Taiwan & 120.71 & 21.98 & 12.29 & 2.6720 & 1.6298 \\
\hline $\mathrm{HC}$ & Taiwan & 120.80 & 21.93 & 12.24 & 2.2661 & 1.2238 \\
\hline ELB & Taiwan & 120.80 & 21.90 & 12.20 & 2.3581 & 1.3156 \\
\hline PHU & Vietnam & 105.95 & 21.02 & 10.92 & 1.0146 & -0.0326 \\
\hline
\end{tabular}





Fig. 1. Maps of the locations with regards to 12 permanent, 8 temporary, and 2 international stations. The blue (red) circles denote the temporary (permanent and international) stations.

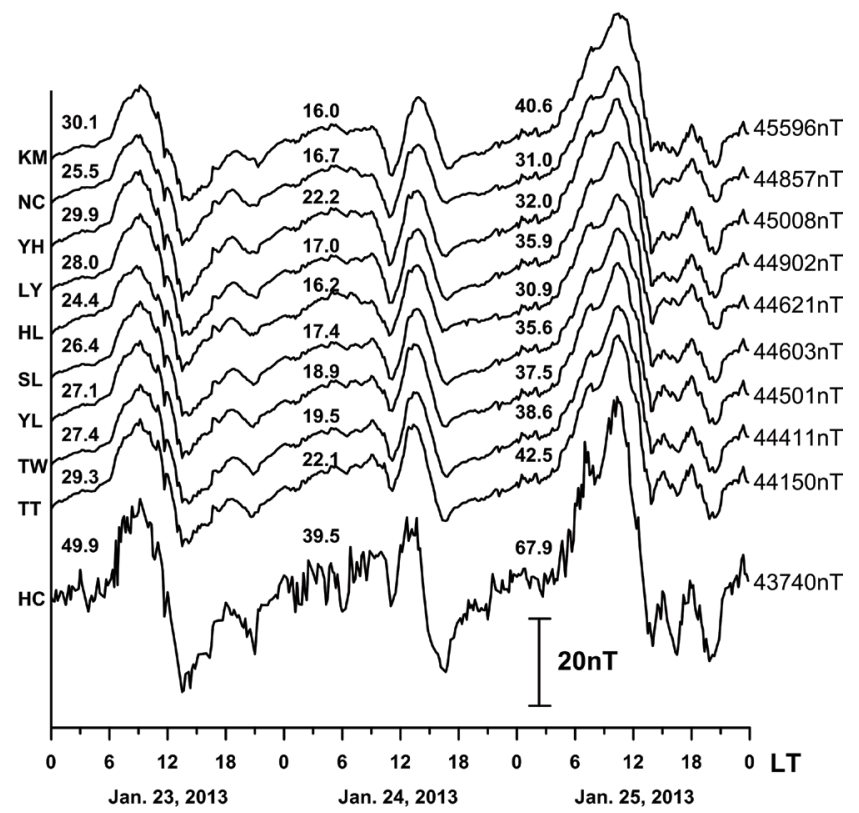

Fig. 2. Changes in geomagnetic total intensity field during $23-25$ January 2013 . The numbers show the range of the diurnal variation at stations on each day.

23 - 25 January 2013 (local time). The geomagnetic field in Taiwan ranges mainly from 43740 - $45596 \mathrm{nT}$ and is proportional to the geomagnetic latitudes. The relationships among the total intensity field, diurnal ranges, and geomagnetic lat- itudes are consistent with those observed in other places in the world (Finlay et al. 2010). The diurnal variation ranges observed at the entire stations were comparable and ranged between 16.0 - $30.1 \mathrm{nT}$ on 23 - 24 January 2013, except for 
the 39.5 and $49.9 \mathrm{nT}$ ranges at the HC station (Fig. 2). On 25 January 2013, intense disturbances from solar activities resulted in large diurnal variations ranging from 30.9 and $42.5 \mathrm{nT}$ at all stations except for the HC station. On this day the diurnal variation range at the $\mathrm{HC}$ station was $67.9 \mathrm{nT}$. This was about 2 times the value at the other stations. To examine whether the global effects dominated the unusually large range at the $\mathrm{HC}$ station the yearly values at all stations in Taiwan were used to construct the isomagnetic chart shown in Fig. 3 (Chapman and Bartels 1940). The modeled values derived from IGRF were also taken into consideration and further compared with observational data in Taiwan. That the smallest and largest intensity fields can be found at the southern end of the $\mathrm{HC}$ (the geomagnetic latitude $=12.24^{\circ}$ ) and at the northern end of the NC (the geomagnetic latitude $=15.02^{\circ}$ ) stations is consistent with the observation and modeled values (Fig. 3). The agreements suggest that the yearly values and/or the total intensity in the geomagnetic field observation at the $\mathrm{HC}$ station are normal. The unusually large diurnal ranges at the $\mathrm{HC}$ station are related to neither the solar activities nor the Earth's main geomagnetic field. The large diurnal ranges suggest domination by local effects.

To clarify that the large diurnal changes at the $\mathrm{HC}$ station are produced by local effects, the GZH and PHU stations with geomagnetic latitudes of about $12.24^{\circ}$, which is very similar to the $\mathrm{HC}$ station, were also used in further examinations. Figure 4 shows the changes in the total intensity field at the GZH, PHU, and $\mathrm{HC}$ stations during 23 - 25 January 2013 (local time). The changes in the total intensity at the GZH and PHU stations are very similar to those at the $\mathrm{HC}$ station. However, the ranges at the $\mathrm{HC}$ station are also about 2 times larger than those at the GZH and PHU stations on each day. The diurnal ranges at the GZH and PHU stations are very similar to those at other stations in northern Taiwan. This suggests that the unusual ranges are not dominated by the Earth's main field. The geomagnetic latitude effects on the diurnal ranges are estimated using the permanent stations, except for the HC station. We used the diurnal ranges at the $\mathrm{NC}$ station as a reference. The ranges from other stations are divided by the reference on the particular day to obtain the ratios for normalization due to solar activities. Figure 5 shows the relationships between the ratios and the geomagnetic latitudes. The ratios are inversely proportional to the geomagnetic latitudes, consistent with previous studies (Chapman and Bartels 1940). It is obvious that the inverse relationship can be roughly constructed using those stations. The ratio, which is obviously larger than an estimated value against the relationship, can be found at southern Taiwan, particularly at the HC station. Thus, the geomagnetic latitude is not the major factor in the unusual ranges from the diurnal variations in southern Taiwan. We further established 8 temporary stations on the Hengchun peninsula to examine the unusual diurnal ranges, which can be observed from areas nearby the HC station or evenly covering the Hengchun peninsula. The diurnal ranges obtained from the 8 temporary stations are also divided by the reference. The derived ratios are significantly larger than those at the stations located in central and northern Taiwan and the 2 international stations (i.e., GZH and PHU) (Fig. 5). The ratio differences are derived by subtracting the estimated values from the relationship to remove the Earth's main field effects and the solar activities for understanding the possible mechanisms of this unusual phenomenon (Fig. 6). The contour line with ratio differences of 0.2 is close to the

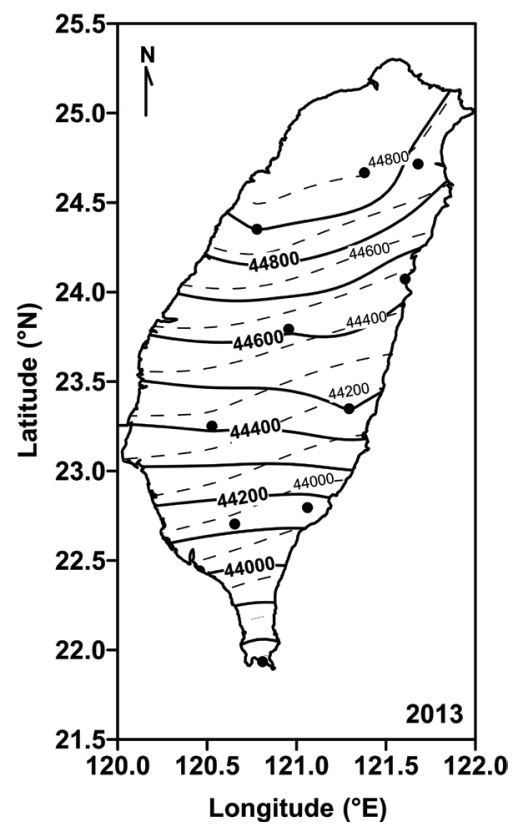

Fig. 3. The comparison between the observation and modeled values in the geomagnetic total intensity field in Taiwan. The solid and dashed lines denote the observation and modeled values, respectively.

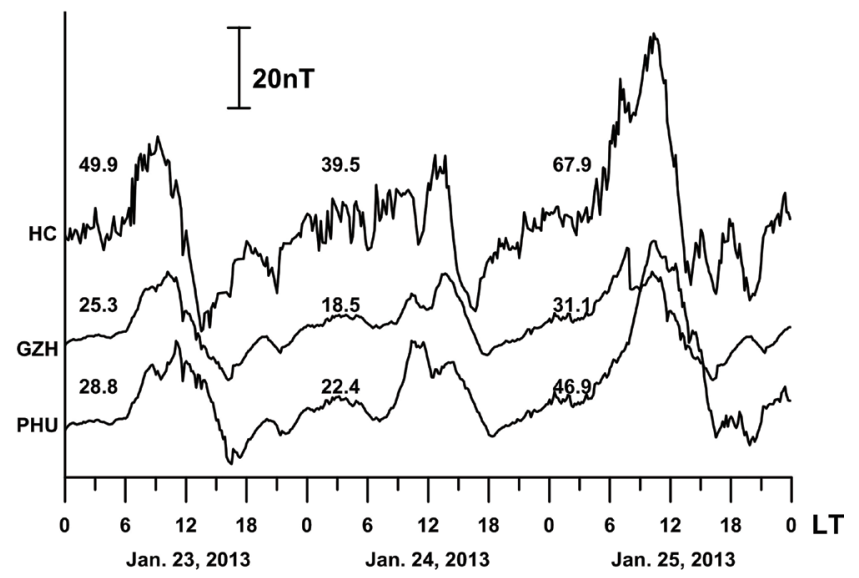

Fig. 4. Changes in geomagnetic total intensity field at the HC, GZH, and PHU stations during 23 - 25 January 2013. The numbers show the range of diurnal variation at the $\mathrm{HC}, \mathrm{GZH}$, and PHU stations on each day. 


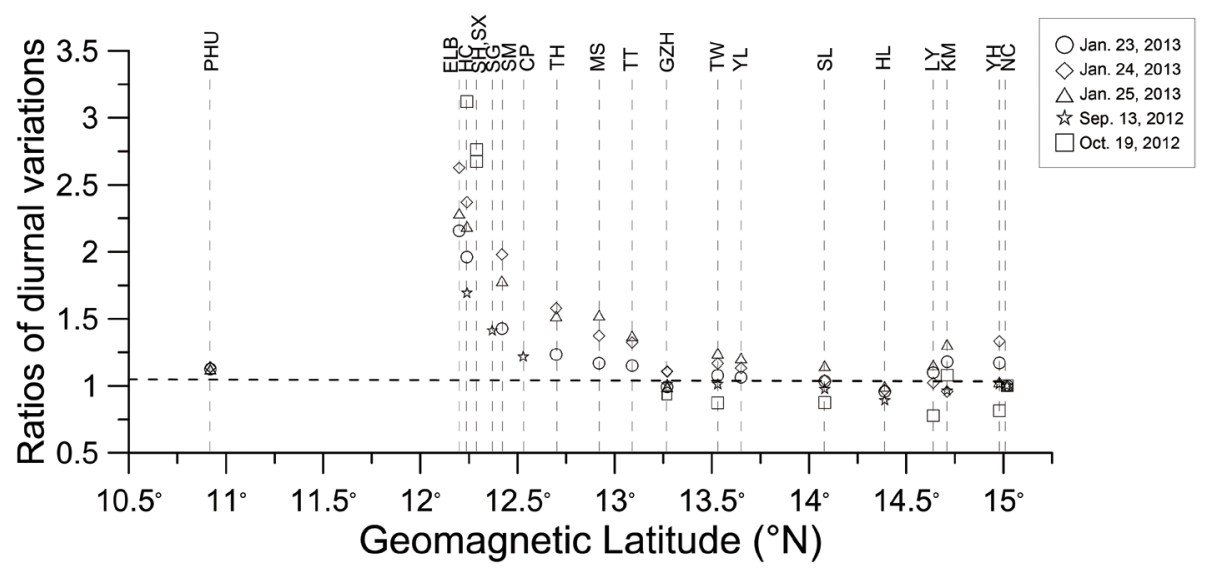

Fig. 5. The relationship between the ratios and geomagnetic latitudes. The horizontal dashed line denotes the inverse proportional relationship between the ratio and the geomagnetic latitudes.

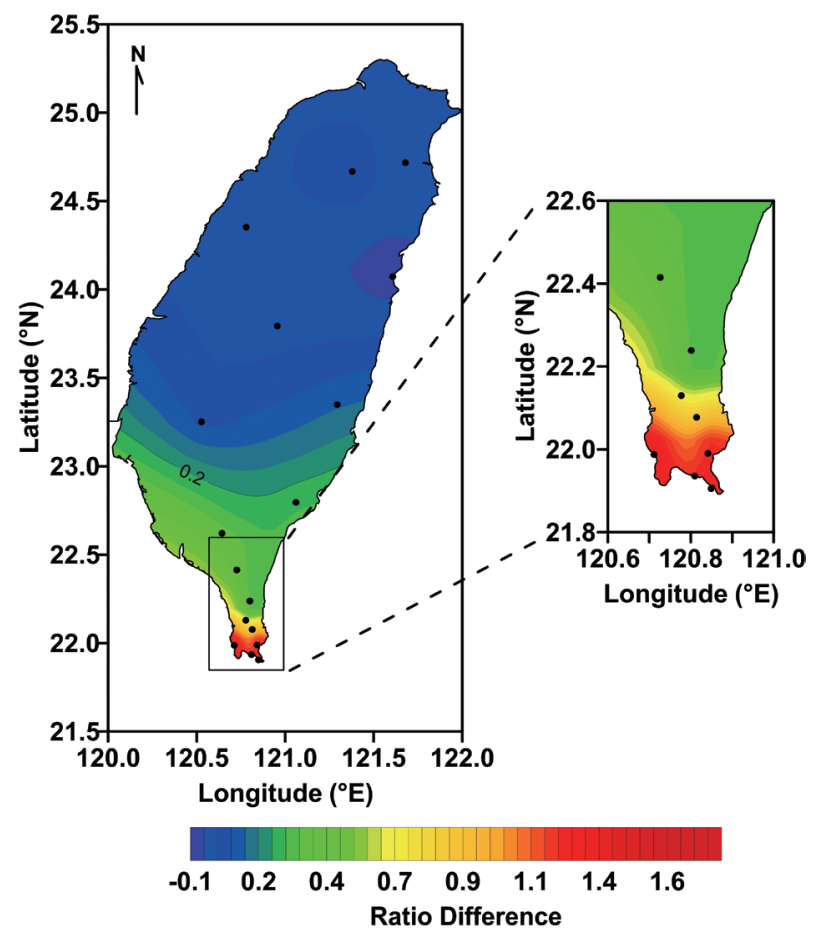

Fig. 6. The ratio differences in Taiwan.

$23^{\circ}$ latitude. The ratio differences are rather small in northern Taiwan. The ratio differences of $>0.2$, which suggest the unusual diurnal ranges, are distributed mainly in areas where the latitude $<23^{\circ}$ in Taiwan. The biggest ratio difference of 1.72 was observed at the SX station on the Hengchun peninsula, which is just about $600 \mathrm{~m}$ away from the closest coastline. The $\mathrm{SH}$ station with a ratio difference of 1.62 is located at the opposite side on the western Hengchun peninsula with almost the same geomagnetic latitude with station SX. The ELB and HC stations, which are only 200 and $800 \mathrm{~m}$ away from the closest coastline, have 1.31 and 1.22 ratio differences, respectively. A common factor of these ELB, HC, SH, and SX stations is they are all a short distance away from the coastline. Thus, the highly conductive sea water should dominate the large diurnal ranges on the Hengchun peninsula.

\section{DISCUSSION AND CONCLUSIONS}

Variations in the geomagnetic field are dominated by various kinds of sources. The most powerful natural source is solar activity which constantly bombard the Earth's magnetosphere and interacts with the Earth's geomagnetic fields (Chapman and Miller 1940). The variations in the 
geomagnetic field caused by solar activity are most likely the same within a small region generally considered to be global effects (Chapman and Bartels 1940). Other sources such as induced geomagnetic fields caused by differences in electrical structure (Lilley and Arora 1982; Lilley 1984; Horng et al. 1992; Hsu et al. 1998; Lilley et al. 1999; Yen et al. 2009), pre-earthquake magnetic anomalies resulting from stressed rocks (Yanagihara and Nagano 1976; Rikitake 1979; Shiraki 1980; Chen and Fung 1985; Gong 1985; Chen et al. 2006), and the magnetic coast effect due to the distinct conductivity between continental rocks and sea water (Parkinson 1959, 1962, 1983; Bennett and Lilley 1971; Lilley and Bennett 1972; Parkinson and Jones 1979; Delaurier et al. 1983; Yukutake et al. 1983; Ogawa et al. 1986; EMSLAB Group 1988; White et al. 1990; Kellett et al. 1991; Hitchman et al. 2000; Armadillo et al. 2001; Lee et al. 2007; Bertrand et al. 2009, 2012; Chiang et al. 2010) affect the geomagnetic field within a local area. The GZH, HC, and PHU stations have similar geomagnetic latitudes from $10.92-13.27^{\circ} \mathrm{N}$. The small ratios of 1.05 and 1.01 at GZH and PHU, respectively, yield small differences in the estimated values (Fig. 5). The small ratio differences of 0.01 and -0.03 were obtained at the GZH and PHU stations, respectively, and the relatively-large ratio difference of 1.22 was derived at the HC station. This is not a global effects but a local effect. The local effects have ratio differences of $>0.2$ distributed mainly on the Hengchun peninsula. The Hengchun peninsula, which is only $15 \mathrm{~km}$ in the $\mathrm{N}-\mathrm{S}$ direction and $20 \mathrm{~km}$ in the E-S direction, is surrounded by the South China Sea, Bashi Channel, and Pacific Ocean. The Hengchun peninsula is strongly influenced by the ocean and the magnetic coast effect is a factor in the particularly large geomagnetic differences.

Parkinson (1959) found that the vertical component of the time-varying geomagnetic field can be modified once secondary magnetic fields are induced by non-uniform conductivity structures. Coastlines, which are the juxtaposition of sea water, the oceanic lithosphere and the continental lithosphere, are common non-uniform conductivity structures. The induction field directions are likely toward the coastlines due to good sea water conduction. This is named the magnetic coast effect. The magnetic coast effect can be evaluated by fluctuations in the geomagnetic field on the vertical component $(\mathrm{Z})$, the horizontal component $(\mathrm{H})$, and the declination field (D) within a short temporal period. In practice, using the Fourier transform those fluctuations are replaced by the geomagnetic data amplitude in particular frequency bands. Thus, the ranges in diurnal variation used in this study approach the magnetic coast effect evaluated using the geomagnetic field amplitude at the one-day frequency band. Thong (2009) constructed a three-dimensional forward model to study the coast effect on magnetotelluric data on Taiwan Island. The bathymetry around Taiwan is described using the grid resolution of $10 \times 10 \mathrm{~km}^{2}$ and the resistivity for the ocean is assumed to be $0.3 \Omega \mathrm{m}$. The mod- eling results show that the coast effect on magnetotelluric data is generally significant for periods $>10000 \mathrm{~s}$ that has an agreement with the one-day frequency band in this study. Hitchman et al. (2000) analyzed the geomagnetic data recorded with a line of ten three-component magnetometers from inland southeastern Australia, across the coastline, to the deep Tasman Sea. The data recorded at the stations located nearby the coastline presented great changes in amplitude in the vertical component, which significantly contributes to the geomagnetic total intensity field. Hitchman et al. (2000) showed that the magnetic coast effect can intensely affect areas with distances of about $250 \mathrm{~km}$ away from coastlines in Australia. The longest distances away from the sea water in Taiwan is about $75 \mathrm{~km}$. This suggests that all of Taiwan should be entirely affected by the magnetic coast effect and not isolated just at Hengchun peninsula. However, it is very difficult to clarify that the magnetic coast effect on all of Taiwan Island without three-component magnetometers. In this study the intense and/or obvious magnetic coast effect on Hengchun peninsula can be observed. The magnetic field at stations located very close to the coastline, particularly on the Hengchun peninsula, is intensely affected.

The long-term magnetic problem of the large diurnal ranges in southern Taiwan is caused by the magnetic coast effect. Three-component fluxgate magnetometers should be employed to clarify and/or quantify the magnetic coast effect on the entirety of Taiwan Island. A simulated model of the magnetic coast effect in the Taiwan area could be developed once non-uniform conductivity structures along the coastline can be accurately investigated using fluxgate magnetometers.

Acknowledgements The authors appreciate the valuable comments raised by the Tan-Kin Wang, Lun-Tao Tong, and an anonymous reviewer to greatly improve the manuscript and wish to express their appreciation to the Central Weather Bureau for providing high quality geomagnetic data.

\section{REFERENCES}

Armadillo, E., E. Bozzo, V. Cerv, A. De Santis, D. Di Mauro, M. Gambetta, A. Meloni, J. Pek, and F. Speranza, 2001: Geomagnetic depth sounding in the Northern Apennines (Italy). Earth Planets Space, 53, 385-396, doi: 10.1186/BF03352395. [Link]

Bennett, D. J. and F. E. M. Lilley, 1971: The effect of the south-east coast of Australia on transient magnetic variations. Earth Planet. Sci. Lett., 12, 392-398, doi: 10.1016/0012-821X(71)90023-9. [Link]

Bertrand, E., M. Unsworth, C. W. Chiang, C. S. Chen, C. C. Chen, F. Wu, E. Türkoğlu, H. L. Hsu, and G. Hill, 2009: Magnetotelluric evidence for thick-skinned tectonics in central Taiwan. Geology, 37, 711-714, doi: 10.1130/G25755a.1. [Link] 
Bertrand, E. A., M. J. Unsworth, C. W. Chiang, C. S. Chen, C. C. Chen, F. T. Wu, E. Türkoğlu, H. L. Hsu, and G. J. Hill, 2012: Magnetotelluric imaging beneath the Taiwan orogen: An arc-continent collision. J. Geophys. Res., 117, B01402, doi: 10.1029/2011jb008688. [Link]

Chapman, S. and J. Bartels, 1940: Geomagnetism: Geomagnetic and Related Phenomena, Oxford Univ. Press, Oxford, Landon, 1049 pp.

Chapman, S. and J. C. P. Miller, 1940: The statistical determination of lunar daily variations in geomagnetic and meteorological elements. Geophys. Suppl. MNRAS, 4, 649-669, doi: 10.1111/j.1365-246X.1940.tb02923.x. [Link]

Chen, C. H., J. Y. Liu, H. Y. Yen, X. Zeng, and Y. H. Yeh, 2004: Changes of geomagnetic total field and occurrences of earthquakes in Taiwan. Terr. Atmos. Ocean. Sci., 15, 361-370.

Chen, C. H., C. R. Lin, H. L. Chao, H. Y. Yen, J. Y. Liu, and Y.H. Yeh, 2009: Evaluation of the applicability of the Chapman-Miller method on variation of the geomagnetic total intensity field in Taiwan from 1988 to 2007. Terr. Atmos. Ocean. Sci., 20, 799-806, doi: 10.3319/ TAO.2009.02.03.01(T). [Link]

Chen, C. H., J. Y. Liu, P. Y. Lin, H. Y. Yen, K. Hattori, W. T. Liang, Y. I. Chen, Y. H. Yeh, and X. Zeng, 2010: Pre-seismic geomagnetic anomaly and earthquake location. Tectonophysics, 489, 240-247, doi: 10.1016/j. tecto.2010.04.018. [Link]

Chen, C. H., S. Wen, J. Y. Liu, T. K. Yeh, C. H. Wang, H. Y. Yen, K. Hattori, and C. R. Lin, 2011: Seismomagnetic signal comparison using the Morlet wavelet method. Disaster Adv., 4, 53-60.

Chen, C. H., J. Y. Liu, T. M. Chang, T. K. Yeh, C. H. Wang, S. Wen, H. Y. Yen, K. Hattori, C. R. Lin, and Y. R. Chen, 2012: Azimuthal propagation of seismo-magnetic signals from large earthquakes in Taiwan. Ann. Geophys., 55, 63-71, doi: 10.4401/ag-5326. [Link]

Chen, C. H., H. L. Hsu, S. Wen, T. K. Yeh, F. Y. Chang, C. H. Wang, J. Y. Liu, Y. Y. Sun, K. Hattori, H. Y. Yen, and P. Han, 2013: Evaluation of seismo-electric anomalies using magnetic data in Taiwan. Nat. Hazards Earth Syst. Sci., 13, 597-604, doi: 10.5194/nhess13-597-2013. [Link]

Chen, C. H., C. H. Wang, L. C. Lin, H. H. Hsieh, H. Y. Yen, and M. H. Shih, 2014: Typhoon-induced magnetic disturbances: Cases in the Western Pacific. Terr. Atmos. Ocean. Sci., 25, 647-653, doi: 10.3319/ TAO.2014.05.08.01(AA). [Link]

Chen, K. J., B. Chiu, and C. H. Lin, 2006: A search for a correlation between time change in transfer functions and seismic energy release in northern Taiwan. Earth Planets Space, 58, 981-991, doi: 10.1186/BF03352603. [Link]
Chen, P. F. and P. C. W. Fung, 1985: Significance of the sign changing of the imaginary arrows in geomagnetic induction investigation. Geophys. J. Int., 80, 257-263, doi: 10.1111/j.1365-246X.1985.tb05089.x. [Link]

Chiang, C. W., C. C. Chen, M. Unsworth, E. Bertrand, C. S. Chen, T. D. Kieu, and H. L. Hsu, 2010: The deep electrical structure of southern Taiwan and its tectonic implications. Terr. Atmos. Ocean. Sci., 21, 879-895, doi: 10.3319/TAO.2010.02.25.01(T). [Link]

Delaurier, J. M., D. R. Auld, and L. K. Law, 1983: The geomagnetic response across the continental margin off Vancouver Island: Comparison of results from numerical modelling and field data. J. Geomag. Geoelectr., 35, 517-528, doi: 10.5636/jgg.35.517. [Link]

EMSLAB Group, 1988: The EMSLAB electromagnetic sounding experiment. Eos, Trans., AGU, 69, 89-99, doi: 10.1029/88EO00060. [Link]

Finlay, C. C., S. Maus, C. D. Beggan, T. N. Bondar, A. Chambodut, T. A. Chernova, A. Chulliat, V.P. Golovkov, B. Hamilton, M. Hamoudi, R. Holme, G. Hulot, W. Kuang, B. Langlais, V. Lesur, F. J. Lowes, H. Lühr, S. Macmillan, M. Mandea, S. McLean, C. Manoj, M. Menvielle, I. Michaelis, N. Olsen, J. Rauberg, M. Rother, T. J. Sabaka, A. Tangborn, L. Tøffner-Clausen, E. Thébault, A. W. P. Thomson, I. Wardinski, Z. Wei, and T. I. Zvereva, 2010: International Geomagnetic Reference Field: The eleventh generation. Geophys. J.Int., 183, 1216-1230, doi: 10.1111/j.1365-246X.2010.04804.x. [Link]

Gong, S., 1985: Anomalous changes in transfer functions and the 1976 Tangshan earthquake $\left(M_{\mathrm{S}}=7.8\right)$. J. Geomag. Geoelectr, 37, 503-508, doi: 10.5636/ jgg.37.503. [Link]

Hitchman, A. P., P. R. Milligan, F. E. M. Lilley, A. White, and G. S. Heinson, 2000: The total-field geomagnetic coast effect: The CICADA97 line from deep Tasman sea to inland New South Wales. Explor. Geophys., 31, 52-57, doi: 10.1071/EG00052. [Link]

Horng, C. S., C. Laj, T. Q. Lee, and J. C. Chen, 1992: Magnetic characteristics of sedimentary rocks from the Tsengwen-chi and Erhjen-chi sections in southwestern Taiwan. Terr. Atmos. Ocean. Sci., 3, 519-532.

Hsieh, H. H., C. H. Chen, P. Y. Lin, and H. Y. Yen, 2014: Curie point depth from spectral analysis of magnetic data in Taiwan. J. Asian Earth Sci., 90, 26-33, doi: 10.1016/j.jseaes.2014.04.007. [Link]

Hsu, S. K., C. S. Liu, C. T. Shyu, S. Y. Liu, J. C. Sibuet, S. Lallemand, C. Wang, and D. Reed, 1998: New gravity and magnetic anomaly maps in the Taiwan-Luzon region and their preliminary interpretation. Terr. Atmos. Ocean. Sci., 9, 509-532.

Kellett, R. L., F. E. M. Lilley, and A. White, 1991: A two-dimensional interpretation of the geomagnetic coast effect of southeast Australia, observed on land 
and seafloor. Tectonophysics, 192, 367-382, doi: 10.1016/0040-1951(91)90110-E. [Link]

Lee, T. J., Y. Song, and T. Uchida, 2007: Three-dimensional magnetotelluric surveys for geothermal development in Pohang, Korea. Explor. Geophys., 38, 89-97, doi: 10.1071/EG07004. [Link]

Lilley, F. E. M., 1984: On the spatial pattern of magnetic fluctuations in the Cobar area, NSW. Explor. Geophys., 15, 79-83, doi: 10.1071/EG984079. [Link]

Lilley, F. E. M. and D. J. Bennett, 1972: An array experiment with magnetic variometers near the coasts of south-east Australia. Geophys. J. Int., 29, 49-64, doi: 10.1111/j.1365-246X.1972.tb06151.x. [Link]

Lilley, F. E. M. and B. R. Arora, 1982: The sign convention for quadrature Parkinson arrows in geomagnetic induction studies. Rev. Geophys., 20, 513-518, doi: 10.1029/ RG020i003p00513. [Link]

Lilley, F. E. M., A. P. Hitchman, and L. J. Wang, 1999: Time-varying effects in magnetic mapping: Amphidromes, doldrums, and induction hazard. Geophysics, 64, 1720-1729, doi: 10.1190/1.1444676. [Link]

Liu, J. Y., C. H. Chen, Y. I. Chen, H. Y. Yen, K. Hattori, and K. Yumoto, 2006: Seismo-geomagnetic anomalies and $M \geq 5.0$ earthquakes observed in Taiwan during 19882001. Phys. Chem. Earth, 31, 215-222, doi: 10.1016/j. pce.2006.02.009. [Link]

Ogawa, Y., T. Yukutake, and H. Utada, 1986: Two-dimensional modelling of resistivity structure beneath the Tohoku district, northern Honshu of Japan, by a finite element method. J. Geomag. Geoelectr., 38, 45-79, doi: 10.5636/jgg.38.45. [Link]

Parkinson, W. D., 1959: Directions of rapid geomagnetic fluctuations. Geophys. J. Int., 2, 1-14, doi: 10.1111/ j.1365-246X.1959.tb05776.x. [Link]

Parkinson, W. D., 1962: The influence of continents and oceans on geomagnetic variations. Geophys. J. Int., 6, 441-449, doi: 10.1111/j.1365-246X.1962.tb02992.x. [Link]

Parkinson, W. D., 1983: Introduction to Geomagnetism, Scottish Academic Press, Edinburgh and London, 433 pp.

Parkinson, W. D. and F. W. Jones, 1979: The geomag- netic coast effect. Rev. Geophys., 17, 1999-2015, doi: 10.1029/RG017i008p01999. [Link]

Rikitake, T., 1979: Changes in the direction of magnetic vector of short-period geomagnetic variations before the 1972 Sitka, Alaska, earthquake. J. Geomag. Geoelectr, 31, 441-448, doi: 10.5636/jgg.31.441. [Link]

Shiraki, M., 1980: Monitoring of the time change in transfer functions in the central Japan conductivity anomaly. J. Geomag. Geoelectr, 32, 637-648, doi: 10.5636/ jgg.32.637. [Link]

Thong, K. D., 2009: Coast effect on magnetotelluric data in Taiwan Island. Master Thesis, National Central University, Taiwan, $100 \mathrm{pp}$.

Wen, S., C. H. Chen, H. Y. Yen, T. K. Yeh, J. Y. Liu, K. Hattori, H. Peng, C. H. Wang, and T. C. Shin, 2012: Magnetic storm free ULF analysis in relation with earthquakes in Taiwan. Nat. Hazards Earth Syst. Sci., 12, 1747-1754, doi: 10.5194/nhess-12-1747-2012. [Link]

White, A., R. L. Kellett, and F. E. M. Lilley, 1990: The continental slope experiment along the Tasman project profile, southeast Australia. Phys. Earth Planet. Inter., 60, 147-154, doi: 10.1016/0031-9201(90)90257-X. [Link]

Yanagihara, K. and T. Nagano, 1976: Time change of transfer function in the central Japan anomaly of conductivity with special reference to earthquake occurrences. J. Geomag. Geoelectr, 28, 157-163, doi: 10.5636/ jgg.28.157. [Link]

Yen, H. Y., C. H. Chen, Y. H. Yeh, J. Y. Liu, C. R. Lin, and Y. B. Tsai, 2004: Geomagnetic fluctuations during the 1999 Chi-Chi earthquake in Taiwan. Earth Planets Space, 56, 39-45, doi: 10.1186/BF03352489. [Link]

Yen, H. Y., C. H. Chen, H. H. Hsieh, C. R. Lin, Y. H. Yeh, Y. B. Tsai, J. Y. Liu, G. K. Yu, and Y. R. Chen, 2009: Magnetic survey of Taiwan and its preliminary interpretations. Terr. Atmos. Ocean. Sci., 20, 309-314, doi: 10.3319/TAO.2008.04.08.01(T). [Link]

Yukutake, T., J. H. Filloux, J. Segawa, Y. Hamano, and H. Utada, 1983: Preliminary report on a magnetotelluric array study in the northwest Pacific. J. Geomag. Geoelectr., 35, 575-587, doi: 10.5636/jgg.35.575. [Link] 